\title{
Residents claim 24-hour call violates Charter rights
}

$\mathrm{M}$ edical residents in the province of Quebec have launched a grievance contending that the 24-hour on-call schedule permitted under their provincial contract violates the Canadian Charter of Rights and Freedoms.

The dispute began with a lone resident, then working at the McGill University Health Centre in Montréal, Quebec. In February, it escalated to involve associations representing residents at the Université de Montréal, McGill, and the University of Sherbrooke, supported by the Fédération des Médecins Résidents du Québec, which represents all residents working at hospitals in the province.

"We're challenging what has been done for decades," says Dr. Martin Bernier, president of the residents' federation, which contends that continuous on-call duty for 24 hours endangers the health of residents. Bernier says studies indicated increased risks of car accidents or self-injury such as needle sticks in doctors who have been sleep-deprived after working more than 16 hours continuously ( $N$ Engl J Med 2005;352:1025-33 and JAMA 2006; 296:1055-62) .

"There is evidence of harm towards the resident," which would violate the Charter's guarantees of personal liberty and security, Bernier says.

Concerns about patient safety have also been raised as other studies point to an increase in adverse events and a failure to recognize the importance of some information after working on-call schedules of 24 hours or more (Clin Orthop Relat Res 2006;449:116-27; $N$ Engl J Med 2004;351:1829-37; N Engl J Med 2004;351:1838-48; and PLoS Med 2006;3[12]:e487). Neither the McGill University Health Centre nor the Quebec Ministry of Health and Social Services would provide responses to the grievance, which is under arbitration.

"Because this case is now before the court we won't comment about it," says Karen White, a ministry spokesperson.

Airline pilots, truck drivers and other professions recognize the safety issues involved in working too many hours and there are regulations in place to prevent that, says Bernier. "One has to recognize that the medical field is sort of lagging behind. As much as we recognize that the work we do is totally different, the recognition is that there are physiological limits to how many hours one person can work in a row."

The residents contend hospitals should move to a 16-hour shift schedule but acknowledge the need for flexibility in different hospital departments.

The current collective agreement governing the residents' working conditions is up for renewal in 2010 . Bernier says the federation hopes the grievance will be settled before that, "but in the meantime a legal question has been asked and we will get to the bottom of it." An arbitration hearing was scheduled for April 7.

Other jurisdictions have limited the work week of residents, Bernier says. In the United Kingdom, legislation taking effect this year prohibits more than

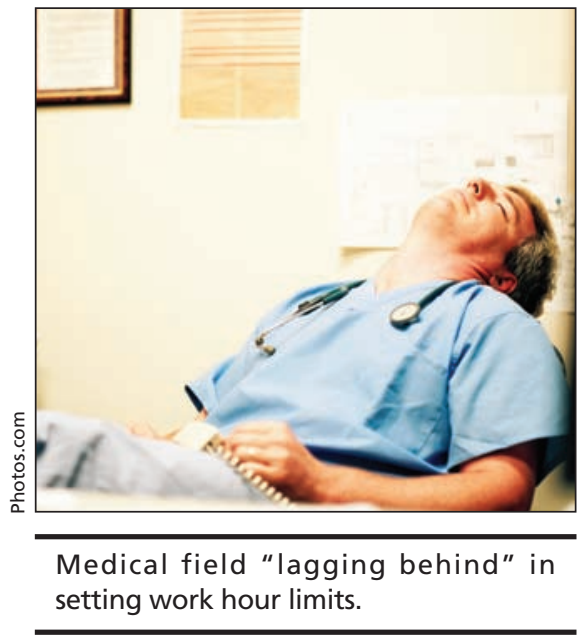

49 hours per week for residents. In parts of Australia, the work week has been limited to 72 hours.

"We're not going to arbitration and court just for the fun of it," Bernier adds. - Laura Eggertson, CMAJ

DOI:10.1503/cmaj.090527

\section{More news@ @www.cmaj.ca}

Casket-cracking: A computed to-
mography scan of an Egyptian
mummy reveals data about ancient
diets and the general health of past
cultures. - Roger Collier, CMAJ

Digital Rx: While the United States moves aggressively to promote e-prescribing, the pace of change is more laid back in Canada. - Laura Eggertson, CMAJ

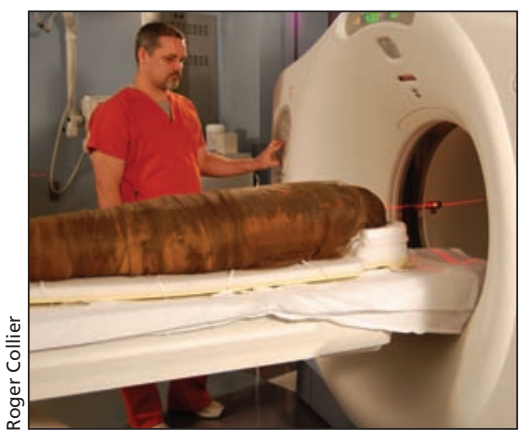

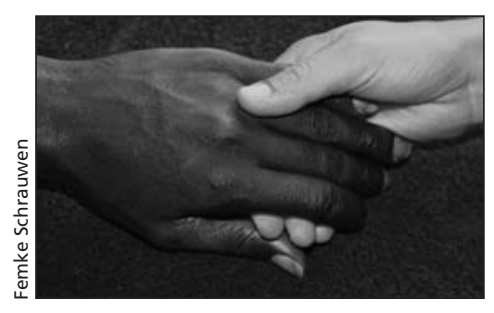

Dispatch: A Canadian physician finds herself in tears over the daily death statistics at a maternity ward in Malawi. Dr. Ilona Hale, Ntcheu District Hospital, Malawi.

Shaken: The death of a homeless man in a hospital emergency room points to inadequacies in Manitoba's system for reporting and investigating medical errors. - Dan Lett, Winnipeg, Man.

DOI:10.1503/cmaj.090584 